\title{
Analitik Hiyerarşi Süreci ile Lojistik Merkezi Yeri Seçimi
}

\section{Selection of Logistics Center Location Using Analytic Hierarchy Process}

\author{
Hamit Erdal, ${ }^{\mathrm{a}}$ Hacer Yumurtacı Aydoğmuş ${ }^{\mathrm{b}^{*}}$

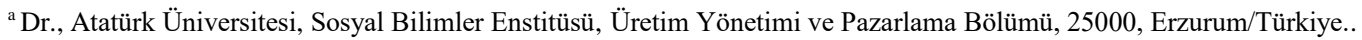 \\ ORCID: 0000-0001-8352-6427 \\ b Dr. Öğr. Üyesi, ALKÜ Rafet Kayış Mühendislik Fakültesi, Kestel Mahallesi No:80 Alanya Antalya. \\ ORCID: 0000-0002-2307-0840
}

\section{MAKALE BILGİSI}

\section{Makale Geçmişi:}

Başvuru tarihi: 01 Ocak 2019

Düzeltme tarihi: 25 Nisan 2019

Kabul tarihi: 03 Mayıs 2019

Anahtar Kelimeler:

Analitik Hiyerarşi Süreci

Lojistik Merkezi

Yer Seçimi

\section{ARTICLE INFO}

Article history:

Received 01 January 2019

Received in revised form 25 April 2019

Accepted 03 May 2019

\section{Keywords:}

Analytic Hierarchy Process

Logistic Center

Location

\section{ÖZ}

Karmaşık bir yapıya sahip olan yer seçimi problemleri uzun yıllardır üzerinde çalışılan bir konu olmuştur. Kamu veya özel kuruluşlar açısından uygun yerin seçimi büyük önem taşımaktadır. Yer seçimi problemleriyle depo, havaalanı, üretim merkezi, lojistik merkezi gibi çeşitli yerlerin konumları en uygun şekilde belirlenmeye çalışılmaktadır. Bu tip problemlerin çözümü için geleneksel ve sezgisel yöntemler geliştirilmiştir. Geliştirilen yöntemler içinde, Çok Kriterli Karar Verme Problemleri'nde (ÇKKV) başvurulan Analitik Hiyerarşi Süreci (AHP) sıklıkla kullanılan yöntemlerden birisidir. Bu çalışmada, ihracat süreçlerinin daha başarılı bir şekilde yönetilmesi ve ihracat potansiyelinin arttırılabilmesi açısından İstanbul Tekstil ve Konfeksiyon İhracatçı Birlikleri (İTKİB) tarafindan yönetilecek ve tekstil sektörüne hizmet verecek bir lojistik merkezin kurulacağ 1 uygun yerin AHP yaklaşımı ile belirlenmesi amaçlanmıştır. Uzman görüşleriyle gerçekleştirilen ikili karşılaştırmalar kullanılarak alternatifler arasında en uygun yer sunulmuştur.

\section{A B S T R A C T}

Location problems with a complex structure have been studied for many years. Choosing right location for public or private organizations has great importance. The most suitable location for warehouses, airports, factories, logistic centers (LC) etc. are tried to be determined by location problems. Traditional and heuristic methods have been developed to solve location problems. The Analytical Hierarchy Process (AHP), which is used in Multi Criteria Decision Making (MCDM) Problems, is one of the commonly used methods. In this study, it is aimed to determine the most suitable LC location that will be managed by Istanbul Textile and Apparel Exporters' Association (ITKIB) and will serve the textile sector by using AHP method in order to manage export processes more successfully and to increase the export potential. The most suitable location among alternatives was recommended by using pairwise comparison with expert opinions.

\section{Giriş}

Yer seçimi (lokasyon) problemi, mevcut kısıtlar ile karar vericinin tercihlerini göz önünde bulundurarak, ele alınan bir bölge için bir alt yapı bileşeninin (zemin, saha, tesis gibi) uygun şekilde konumlandırılmasının belirlenmesinden oluşmaktadır. Evrensel bir karaktere sahip olan bu problem, lojistik açısından da önem taşımaktadır. Lojistik Merkezleri'nin (LM) doğru yerleştirilmesi, tipik lojistik konum problemlerinden birisi olarak literatürde yer almaktadır (Zak ve Węglinski, 2014).
Bilgi teknolojisi ve modern yönetim teorisinin giderek gelişmesiyle birlikte, araştırmacılar hem şirket hem de toplumdaki lojistik yönetimine daha fazla önem vermeye başlamıştır. LM değişmez bir donanım yatırımıdır ve lojistik faaliyetler üzerinde önemli etkiye sahiptir (Chen ve Qu, 2006). Dağıtım ağında yer alan LM'in sayısı ve yeri son ürünün maliyetini doğrudan etkilemektedir. Ayrıca uygun bir LM yerinin seçimi, etkin bir dağıtım ağı için büyük önem taşıyan faktörlerdendir (Tomic vd., 2014).

LM, tüm lojistik faaliyetlerin (nakliye ve sevkiyat, malzeme taşıma, depolama, stok yönetimi, çapraz yerleştirme,

\footnotetext{
* Sorumlu yazar/Corresponding author e-posta: hacer.aydogmus@alanya.edu.tr
} 
intermodall taşımacılık, malların fiziksel dağılımı) ticari olarak yürütüldüğü güvenli bir alanda faaliyet gösteren ayrı bir merkezdir. 3. parti ve 4. parti lojistiklerin modern konseptlerinde LM, müşterilerine kapsamlı ve kaliteli bir hizmet sunan, tüm olası ulaşım modlarını (yol, demiryolu, su ve hava) birbirine bağlayan bir lojistik servis sağlayıcı olarak önemli bir rol oynamaktadır (Zak ve Węglinski, 2014).

Yüzyılı aşkın bir süredir fabrikalar, havaalanları, depolar ve lojistik merkezler için en uygun yerin belirlenmesine yönelik çok sayıda yöntem geliştirilmiştir (Tomic vd., 2014). Literatürde, genetik algoritma, çok amaçlı programlama, çok kriterli karar modeli ve bulanık mantık gibi LM konum seçimi modelini gerçekleştirecek yöntemler bulunmaktadır. Bu yaklaşımların çoğu, karar faktörleri arasındaki küresel ilişkileri göz önünde bulundurmadan sadece problemi çözmek için sistematik prosedürler sağlamaktadır. Oysa karar vericilerin yetenek ve deneyimleri, nihai sonucun performansını önemli ölçüde etkileyebilmektedir. Bu nedenle, potansiyel konumların değerlendirilmesinde hem karar vericilerden hem de uzmanlardan görüşler alınması (Chen ve Qu, 2006) çözüme büyük katkı sağlamaktadır.

Lojistik sistemler, ekonomik kalkınma ve toplumun normal işlevi için vazgeçilmez hale gelmiştir ve LM için uygun saha seçimi, lojistik sistemlerin verimliliği üzerinde doğrudan etkiye sahiptir. $\mathrm{Bu}$ yüzden saha seçimi için bilimsel bir yaklaşım benimsemek gerekmektedir. LM konum seçimi problemi Çok Kriterli Karar Verme (ÇKKV) problemi olarak ele alınabilmektedir (Pramanik vd., 2016).

Karar verme süreci farklı alternatiflerin üretilmesini ve değerlendirilmesini içermektedir. Genellikle, alternatifleri değerlendirmek için birkaç çelişen kriter bulunmaktadır. Örneğin, bir üretim probleminde, üretim oranı, kalite ve operasyon maliyetleri gibi kriterler dikkate alınmaktadır. Söz konusu alternatifler genellikle farklı ÇKKV yöntemleri kullanılarak çeşitli kriterlere göre sıralanabilmektedir. ÇKKV, birden fazla ve genellikle çelişen karar kriterleri altında mümkün olan tüm alternatiflerden en iyi olanı bulmayı ifade etmektedir. Literatürde en fazla göze çarpan ÇKKV yaklaşımlarından biri, faktörler arasındaki nispi ağırlıkları ve bu ağırlıkları temel alan her bir alternatifin toplam değerlerini elde etmeye dayanan Analitik Hiyerarşi Süreci (AHP) yöntemidir (Li-li ve Yan, 2007).

Bu çalışmada uygun LM yer seçimi kararı için AHP yöntemi kullanılmıştır. ÇKKV yöntemi olarak literatürde yer alan bu yöntem ile çalışmada ele alınan problem için karar vermede etkili kriterlerin önem dereceleri analiz edilmiş ve alternatifler puanlarına göre sıralanmıştır. Literatürde farklı sektörlere yönelik LM yer seçimi problemlerinin yer aldığı görülmüş, fakat farklı veri tabanlarında (scopus, sciencedirect) gerçekleştirilen aramada tekstil sektöründe uygulama ile karşılaşılmamıştır. Söz konusu sektör özelinde halen karar desteği sağlamaya yönelik nicel esasların göz önüne alındığı bir uygulamanın bulunmaması nedeniyle bu çalışmanın önem taşıdığı değerlendirilmektedir. Ayrıca sektörden uzmanların görüşlerine dayanarak problemin Çok Kriterli Grup Karar Verme problemi olarak ele alınması da çalışmayı önemli kılan bir başka unsurdur. Çalışmada AHP yönteminin tercih edilmesinin nedeni bu yöntemin geliştirildiği günden itibaren etkin olarak kullanılan, nitel ve nicel kriterlerin bir arada değerlendirilebildiği ve halen sıklıkla başvurulan yöntemlerden biri olmasıdır. Literatür taramasında tesis yeri seçimi problemlerinde artış gösteren bir şekilde bu yönteme başvurulduğu (Şekil 1 ve Şekil 2) ve taramalar sonucunda AHP yönteminin halen çeşitli alanlarda çok sayıda uygulamasının bulunduğu (örneğin scopus üzerinde 2018 yılı için 1523, 2017 y1lı için 1233) görülmüştür.

Çalışmada ilk olarak, tasarlanan LM yapısı ile hemen ardından kısa bir literatür taraması ele alınmış, daha sonra çözüm yönteminin (AHP) adımları, kriterlerin belirlenmesi aşaması ve ele alınan problemin tanımı sunulmuştur. İkili karşılaştırma matrislerine dayanarak gerçekleştirilen AHP yönteminin uygulanması detaylı şekilde anlatıldıktan sonra ise çalışmanın sonuçları üzerinde durulmuştur.

\section{Kavramlar ve Literatür Taraması}

\subsection{Lojistik Merkez Yapıs1}

$\mathrm{Bu}$ başlık altında LM'in sahip olması gereken yapısal özelliklere yer verilmiştir. Tasarlanan LM, İstanbul'da faaliyet yürüten ve İstanbul üzerinden diş piyasaya açılan tüm tekstil firmalarının lojistik fonksiyon alanlarına yönelik taleplerini karşılayacak bir yapıda olmalıdır. Bu doğrultuda, aşağıda detayları sunulan departman/bölümlerin LM'de hizmet vermesi gerekmektedir:

i. Depolar: Hizmete konu ürün tekstil hammaddesi ve nihai üründür. $\mathrm{Bu}$ ürünlerin naylon veya kutular içerisinde ambalajlanması ve aynı şekilde malzeme için en büyük tehditin 1slanma olması sebebiyle, bu malzemenin gerek depolanma, gerek geçici depolanma süreçlerinin kapalı depolarda yapılması gerekmektedir. Kurulması planlanan LM'de sadece malzeme indirme ve bindirmeleri için gerekli aktarma noktaları açık alan olabilir. Diğer tüm depolama ve aktarma noktalarının ise, en azından üstü kapalı yarı açık depolama imkanı sağlaması gerekmektedir. Bu kapsamda inşa edilecek depolar kapalı genel depolar, demir ve karayolu aktarma depoları ile deniz yolu yük aktarma depoları olmak üzere üç başlık altında sıralanmaktadır.

ii. Banka ve postane: LM'de gerek para gerekse kıymetli evrak alım ve göndermeleri için hizmet sağlayacak bu birimler büyük önem taşımaktadır.

iii. Park ve Aktarma Noktalarl: LM'e gelecek tırların gelişinde oluşacak beklemelerin hem maliyete hem çevreye etkisi yadsınamayacak kadar büyüktür. Şehir trafiğinin etkilenmemesi ve sevkiyat hızının korunabilmesi için bu araçlara hizmet sunacak park alanları ile aktarma noktaları kurulmasi gerekmektedir.

iv. Kolaylık Tesisleri: 24 saat esasına göre hizmet sağlayacak bu LM'de hizmetin aksamaması için benzin ve bakım istasyonları ile lokanta ve kafeterya hizmeti sunulması gerekmektedir.

v. Acentalar: Hizmet sağlayıcı idare ve firmaların, müşterileri ile temas noktası olacak idari birimler ve acenta bürolarının bulunası gerekmektedir.

vi. Ofisler: $\mathrm{Bu}$ ofislerin bir kısmı danışmanlık hizmeti ve müşteri memnuniyeti konularında hizmet sunarken, bir kısmı da gümrükleme, sigorta gibi ihracatın olmazsa olmaz ve profesyonel olarak ele alınması gereken konuları üzerinde hizmet vermelidir.

vii. Eğitim ve analiz birimi: $\mathrm{Bu}$ birimde belli zaman aralıklarında rutin ve plansız olmak üzere ihracat potansiyelini artırıcı ve firmaları cesaretlendirici eğitimler verilmelidir. 
Aynı şekilde pazar analizi ve risk analizi konularında uzman desteğinin sağlanacağı birinler bulunması ihracat potansiyelini arttıracaktır.

\subsection{Literatür Taramas1}

Yer seçimi problemleri için çözüm yöntemleri ilk olarak Weber (1909) tarafindan sunulmuş, daha sonraki çalışmalar 1963 ve 1964 yıllarında Cooper tarafından gerçekleştirilmiştir (Tomic vd., 2014). Zaman içerisinde söz konusu problem artan bir ilgiyle üzerinde çalışılan bir problem olarak akademik ve iş çevresinde ele alınmıştır.

Çalışmada çözüm yöntemi olarak ele alınan AHP yöntemi yaklaşık son 40 yıldır bir çok tesis yeri seçiminde etkili bir yöntem olarak kullanılmaktadır. Şekil 1'de Sciencedirect, Şekil 2'de ise Scopus veritabanlarında anahtar kelime, özet ve başlık alanlarında "analitik hiyerarşi süreci" ile metin içinde "yer seçimi" geçen arama sonucu ile y1llara göre AHP yönteminin kullanıldığı yer seçimi çalışmaları grafik olarak sunulmuştur (Bir yayının iki veritabanında da yer almış olabileceği göz önünde bulundurulmalıdır). Bu çerçevede LM yer seçimi problemi için AHP yönteminin kullanılmasının doğru bir karar olduğu değerlendirilmiştir.

Şekil 1. Yıllara göre AHP yönteminin kullanıldığı yer seçimi çalışmaları (Sciencedirect)

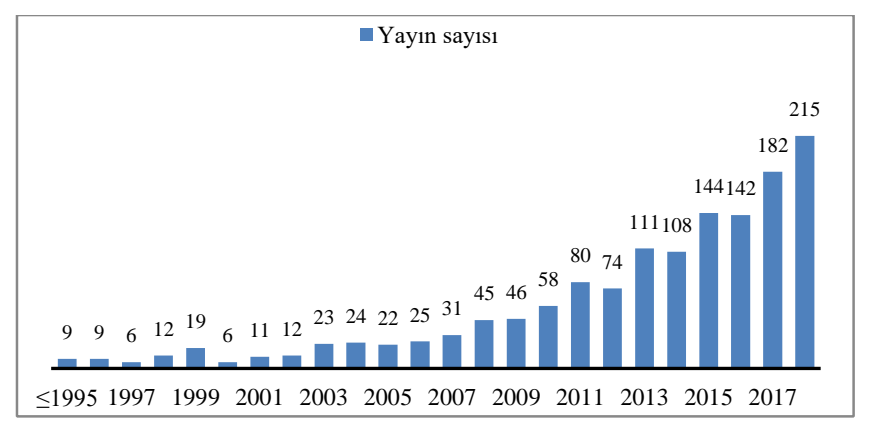

Şekil 2. Yıllara göre AHP yönteminin kullanıldığı yer seçimi çalışmaları (Scopus)

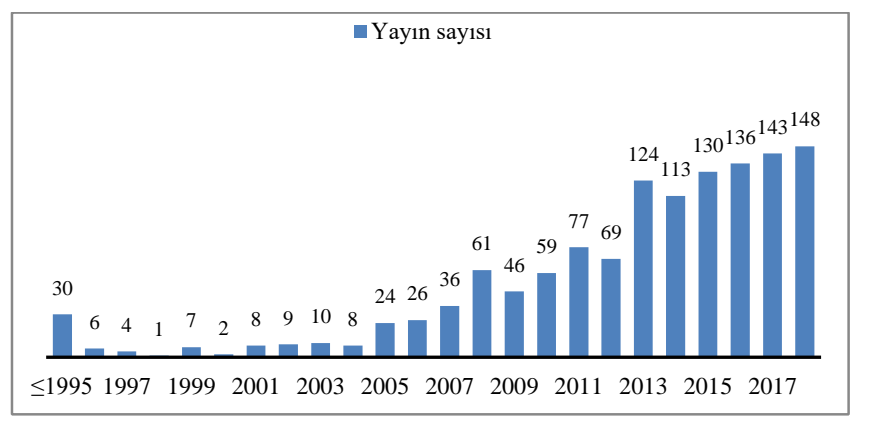

Scopus veri tabanında anahtar kelime, özet ve başlık alanlarında "çok kriterli karar verme" ile "LM yer seçimi" geçen arama sonucuna göre fazla yayın olmamakla birlikte bulunan çalışmalara kısaca değinilmiştir. Zhang ve Pan (2007) lojistik dağıtım merkezlerinin yerini tespit etmek için bir konum değerlendirme indeks sistemi oluşturmuş ve bulanık Delphi yöntemini bir örnek üzerinde kullanmıştır. Turskis ve Zavadskas (2010), ulaştırma, inşaat, ekonomi, teknoloji ve sürdürülebilir kalkınmadaki farklı sorunları çözmek için yeni geliştirilmiş bulanık katkı oranı değerlendirme yöntemini (ARAS-F) sunmuştur. Tu vd. (2010) havaalanı kargo LM yeri seçimi kararı için AHP-Kalite Fonksiyon Yayılımı (KFY) kavramsal modeli uygulamıştır. Bu çalışmada ayrıca sınırlı bütçe tahsisi sorununu çözmek için sıfır-bir hedef programlama (SBHP) ikili modeli uygulanmıştır. Turğut vd. (2011) olası bir deprem sonrasında felaketzedelerin ve kurtarma ekiplerinin ihtiyaçlarını karşılamaya yönelik LM konum seçimi için bulanık AHP'ye dayanan bir karar destek sistemi sunmuştur. Regmi ve Hanaoka (2013), Laos'taki LM'nin yerini analiz etmek için AHP ve HP metodolojilerini kullanmıştır. Liu vd. (2012), Jilin Eyaleti'nin LM'nin saha seçimi için dokuz çeşit yöntemi karşılaştırmıştır. Tomić vd. (2014) Balkan Yarımadası bölgesindeki lojistik merkezler için çevresel faktörleri de göz önünde bulundurarak en uygun yeri bulmaya odaklanmış ve açgözlü sezgisel algoritma ile AHP kullanmıştır. Huang ve Zhu ise 2014 yılında, AHP yöntemi ile Hedef Programlamayı (HP) birlikte ele aldığı bir model sunmuştur. Bozorgi-Amiri ve Asvadi (2015) doğal afetlerin meydana gelmesi durumunda yardım lojistik merkezlerinin (YLM) taşıdığı önemden yola çıkarak AHP yöntemi ile Tahran'da bu merkezlerin yerini bulmaya yönelik örnek uygulama gerçekleştirmiştir. Wang vd. (2016), Kinmen askeri lojistiği için üç alternatif taşıma modunu bulanık AHP metodu ile 4 ana, 13 alt kriter altında değerlendirmiştir. Tang (2016), lojistik ă̆ yapısı tasarımı üzerinde durmuştur. Tehlikeli kimyasal maddelerin lojistiği yeni bir daldır ve bu çalışmada lojistik ağ değerleme kriterlerinin AHP ile ağırlıklandırılması yapılmış, ayrıca çok amaçlı planlama modeli uygulanmıştır. Önden vd. (2018) LM'in uygunluk derecelerinin hesaplanması için üç aşamalı yaklaşım geliştirmişlerdir. Bu çalışmada LM lokasyonlarının değerledirilmesi için coğrafi bilgi sistemleri (CBS) ile entegre olmuş çok kriterli yaklaşım sunulması amaçlanmıştır.

\section{Yöntem}

$\mathrm{Bu}$ bölüm altında çalışmada kullanılan AHP yöntemi ele alınmıştır.

Analitik hiyerarşi süreci, karar vericilerin hedef, kriterler, alt kriterler ve alternatiflerden oluşan hiyerarşik yapıda ki karmaşık bir problemi modellemelerine izin veren ÇKKV yöntemidir. AHP, ikili karşılaştırma matrislerine dayanarak, karar alternatiflerini sıralamak için hem kriterlerin önemini hem de alternatif tercih ölçümlerini tek bir genel skorla birleştirmektedir. AHP, ayrıştırma, karşılaştırmalı yargı ve öncelikli sentez olmak üzere üç ilkeden oluşmaktadır. Ayrıştırma, problemin ortaya konulması için modelin hiyerarşik yapısının inşası ile ilgilidir. En yüksek seviye genel hedefi, orta seviye değerlendirme kriterlerini ve en düşük seviye karar alternatiflerini temsil etmektedir. Şekil 3 'te üç seviyeden oluşan bir AHP yapısı gösterilmiştir. Karşılaştırmalı yarg1, genel hedefe olan katkılarını ölçmek için aynı seviyedeki faktörlerin çift yönlü bir karşılaştırmasıdır. Kriter çiftleri veya alternatifleri karşılaştırılarak bir karşılaştırma matrisi geliştirilmiştir. Son olarak, öncelik sentezi ile karşılaştırma matrisleriyle tanımlanan tercihlere dayanarak, her bir alternatif için bileşik ağırlık hesaplanmaktadır. Bileşik ağırlığın değerine bağlı olarak, her bir alternatifin nispi önceliği elde edilebilmekte ve sonuçların tutarlılığı, tutarlılık oranı (TO) kullanılarak ölçülmektedir. Sonuçları yorumlamak için \%10'dan daha düşük bir TO yeterli kabul edilmektedir (Lee ve Kozar, 2006). 
Şekil 3. Üç Aşamalı Analitik Hiyerarşi Modeli

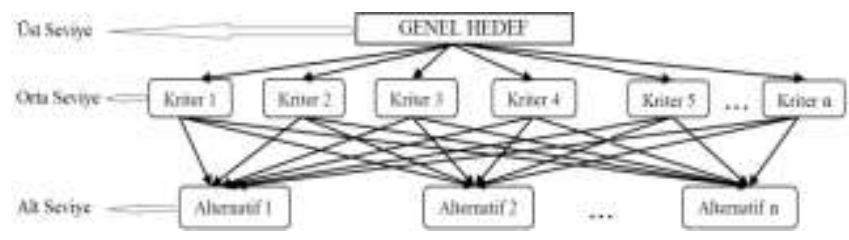

AHP yönteminde ikili karşılaştırma matrislerinde kullanılan önem dereceleri Tablo 1'de gösterilmiştir. Söz konusu tabloda 1 ile 9 arasında değerler bulunmaktadır ve eğer bir faktör ikinciye göre daha önemli ise, o zaman ikinci faktörün birinciye göre önemi onun tersidir (örneğin; $a_{i j}=7$ ise $a_{j i}=1 / 7$ ). İkili karşılaştırma matrislerinde köşegenlerde " 1 ” değeri yer almaktadır.

Öncelik sentezinde bileşik ağırlık hesaplanabilmesi için her ikili karşılaştırma matrisi açısından ayrı ayrı yapılması gereken işlemler kısaca şu şekildedir:

(i) Matris normalize edilir ve satır ortalamaları alınarak matrisin ögelerinin göreli öncelikleri hesaplanır,

(ii) $\mathrm{TO}$ hesaplanır ( $\mathrm{TO}=$ Tutarlılık İndeksi (TI) / Rasgele Tutarlılık İndeksi (RI)),

(iii) Matrisler tutarlı bulunduğu takdirde elde edilen öncelik değerleri kullanılarak her alternatif için bileşik ağırlık (alternatifin puanı) hesaplanır. Matrislerden herhangi birinde kabul edilemez tutarsılık seviyesi ile karşılaşıldığında söz konusu matrislerin ikili karşılaştırmaları güncellenir ve normalize etme işleminden başlayarak işlemlere yeniden devam edilir.

Tablo 1. İkili Karşılaştırmalarda Kullanılan Önem Dereceleri ve Açıklamaları (Saaty, 1990)

\begin{tabular}{|c|c|c|}
\hline $\begin{array}{l}\text { Önem } \\
\text { Derecesi }\end{array}$ & Tanım & Açıklama \\
\hline 1 & Eşit önem seviyesi & $\begin{array}{l}\text { Her iki faktör de hedefe eşit } \\
\text { düzeyde etki yapar. }\end{array}$ \\
\hline 3 & $\begin{array}{l}\text { Orta derecede önem } \\
\text { seviyesi }\end{array}$ & $\begin{array}{l}\text { Tecrübe ve değerlendirmelere göre } \\
\text { bir faktör diğerine göre biraz daha } \\
\text { fazla tercih edilir. }\end{array}$ \\
\hline 5 & Oldukça önemli & $\begin{array}{l}\text { Tecrübe ve değerlendirmelere göre } \\
\text { bir faktör diğerine göre güçlü } \\
\text { şekilde tercih edilir. }\end{array}$ \\
\hline 7 & Çok önemli & $\begin{array}{l}\text { Bir faktör diğerine göre çok güçlü } \\
\text { şekilde tercih edilir. }\end{array}$ \\
\hline 9 & Aşırı önemli & $\begin{array}{l}\text { Bir faktör diğerine göre mümkün } \\
\text { olan en yüksek kabul düzeyinde } \\
\text { tercih edilir. }\end{array}$ \\
\hline $2,4,6,8$ & $\begin{array}{l}\text { Ardışık iki yargı } \\
\text { arasında yer alan ara } \\
\text { değerler }\end{array}$ & Uzlaşma gerektiğinde kullanılırlar \\
\hline
\end{tabular}

TO hesaplaması için, ikili karşılaştırma matrisinin ağırlık sütun vektörünün elemanlarının toplamı $n_{\text {maks }}$ olmak üzere, TI ile RI aşağıdaki formüllerde verildiği gibi hesaplanmalıdır (Taha, 2000):

$$
\begin{gathered}
T I=\frac{n_{\text {maks }}-n}{n-1} \\
R I=\frac{1,98(n-2)}{n}
\end{gathered}
$$

\section{Uygulama}

$\mathrm{Bu}$ bölümde ilk olarak ele alınan problemin tanımı verilmiş, ardından kullanılan kriterler sunulmuş ve AHP yönteminin uygulama aşamaları tablolar halinde verilmiştir.

\subsection{Problemin Tanımı}

İstanbul'da faaliyetlerine devam eden ve 6 Kasım 2018 tarihi itibariyle İstanbul Tekstil ve Konfeksiyon İhracatçı Birlikleri'ne (İTKİB) üye tekstil firması sayıs1 20573'dir (İTKİB, 2018). $\mathrm{Bu}$ firmalardan beşinin üst düzey yöneticileriyle yapılan görüşme neticesinde İstanbul'da tekstil sektöründe faaliyetlerine devam eden on binlerce firma olduğu fakat bu firmaların ihracat sürecinde başa çıkmaları gereken lojistik fonksiyon alanlarında yetersiz bilgi sahibi olmaları nedeniyle ihracat yapamadıkları, ayrıca ihracatçı firmaların bir çoğunun da benzer riskler ve korkular nedeniyle yeni pazar arayışlarına giremedikleri tespit edilmiştir.

$\mathrm{Bu}$ kapsamda İTKİB tarafindan yönetilecek ve tekstil sektörüne hizmet verecek bir LM kurulması ile tekstil firmalarının ihracat potansiyelinin profesyonel bir yönetim anlayışıyla arttırılabileceği ve mevcut riskler ile maliyetlerin düşürülebileceği değerlendirilmektedir. 1937 yılında kurulan İTKİB tarafından üyelerine sağlanan başlıca destek konuları "ticareti geliştirme faaliyetleri, istatistik kayıtları, ekonomik araştırmalar ve raporlama, eğitim faaliyetleri, danışmanlık hizmetleri, koordinasyon faaliyetleri, yayın faaliyetleri, dahilde işleme rejimi ve ihracatın desteklenmesi" şeklinde sıralanmaktadır (İTKİB, 2014). Bu başlıklar incelendiğinde icraya yönelik pek bir faaliyetin bulunmadığı görülmektedir.

İstanbul'da belirlenecek bir noktada tekstil firmalarına hizmet verecek bir LM kurulmasıyla, dış ticaret sürecinde firmaların karşılaşabileceği sorunlara yönelik bir yapılanma ve hizmet sağlanarak hem İstanbul gibi küresel bir merkezin rahatlatılması hem de ihracat potansiyelinin artırılması sağlanabilecektir. Böylece firmalar, yeni piyasalara açılarak hem satışlarını hem de tecrübelerini arttırmış olacaklardır.

Yeni piyasalar; iç piyasada daha önce ulaşılmamış yerler veya ihracat yapılabilecek diş piyasalar olarak değerlendirilebilmektedir. Ancak firmaların yeni piyasalara açılmaları konusunda isteksiz davranmalarına neden olan bazı sebepler bulunmaktadır. İşletmelerin bir kısmı ihracat konusunda aktif ve girişken bir tavır içerisinde olurken, bir diğer kısmı ise ihracat konusunda çekingen ve isteksiz davranmaktadır. İşletmeleri ihracatta engelleyen veya ihracata yönelmeyi isteksiz kılan başlıca nedenler Atabay (2005) tarafından şu şekilde sıralanmıştır:

(i) Sınırlı İstek;

- İç pazarın olanaklarının yeterli/doyurucu olmas1,

- İç pazardaki sorunlarla uğraşma,

- Zaman ayiramama

(ii) Dış Pazar Olanakları Hakkında Bilgi Sahibi Olmama;

- İhracat olanakları hakkında bilgi eksikliği,

- İhracat pazarlarının yeterli büyüklükte algılanmaması veya ihracat işinin pahalı ve riskli algılanması,

(iii) Yeterli Kaynakların Olmaması; 
- Kaliteli personel bulunmamas1,

- İhracat yönetmelikleri hakkında bilgi yetersizliği,

- Sermaye yetersizliği,

- Teknoloji ve üretim konusundaki yetersizlikler,

(iv) Gerçekçi Olmayan Korkular;

- Farklı kültür/dil,

- Döviz işlerinin karışıklığı,

- Nakliye/ulaşım sorunları,

- Dış pazarlardaki istikrarsızlık,

- Dış rekabetin yoğunluğu

(v) Başa çıkamama korkusu.

LM; pazar analizi, risk yönetimi, nakliye, gümrükleme, elleçleme, depolama ve sigortalama konularında firmalara hizmet sağlayarak bu eksiklikleri, kümelemenin sağladığı fiyat avantaj1 ve risk minimizasyonu ile giderebilmektedir.

\subsection{Kriterlerin Belirlenmesi}

LM seçimi problemine etki eden faktörlerin tespitine yönelik literatür taraması gerçekleştirilmiş ve elde edilen kriterlerin gerçek hayat problemine uygunluğunu test etmek için tekstil sektöründe faaliyetlerine 20 seneden daha uzun bir süredir devam eden 5 firma yetkilisi ile yüz yüze görüşmeler gerçekleştirilmiştir. Kriterlerin değerlendirilmesi ve yer seçimi çalışması uzman olarak nitelendirilen bu beş yetkilinin görüşlerine göre şekillenmiştir.

Google Akademik ve Ulusal Tez Veritabanları farklı anahtar sözcükler kullanılarak taranmış ve LM yer seçimi problemi için literatürde kullanılan ve ilerleyen aşamalarda modelde kullanılacak kriterler tespit edilmiştir. Söz konusu kriterlerin gerçek hayat probleminde geçerliliğini tespit etmek amacıyla uzmanlarla görüşülmüş ve İstanbul için uygun olmayan birtakım kriterler bu çalışma kapsamının dışında tutulmuştur. Elde edilen kriterler Tablo 2'de sunulmuştur.

Tablo 2. LM Yer Seçimi Problemine Etki Eden Kriterler (Aydın ve Öğüt, 2008; Tanyaş ve Arıkan, 2013)

\begin{tabular}{|c|c|c|c|c|}
\hline HEDEF & \multicolumn{4}{|c|}{ En Uygun Lojistik Merkezi Yer Seçimi } \\
\hline $\begin{array}{c}\text { ANA } \\
\text { KRİTERLER }\end{array}$ & Maliyetler & Arazi & Konum & $\begin{array}{l}\text { Sosyo- } \\
\text { Ekonomik } \\
\text { Faktörler }\end{array}$ \\
\hline $\begin{array}{c}\text { ALT } \\
\text { KRITTERLER }\end{array}$ & $\begin{array}{l}\text { - Arazi } \\
\text { - Tesis } \\
\text { İnşaatı } \\
\text { - Hizmet } \\
\text { - Kamulaş- } \\
\text { tırma }\end{array}$ & $\begin{array}{l}\text { - Büyüklüğü } \\
\text { - Genişleme } \\
\text { Olanakları } \\
\text { - Altyapı } 1 \\
\text { Yeterliliği } \\
\text { - Topoğrafik } \\
\text { Özellikler }\end{array}$ & $\begin{array}{l}\text { •Üretim } \\
\text { Merkezlerine } \\
\text { Yakınlık } \\
\text { (ÜMY) } \\
\text { •Pazara } \\
\text { Yakınlık (PY) } \\
\text { •Havalimanın } \\
\text { a Yakınlık } \\
\text { (HY) } \\
\text { •Limana } \\
\text { Yakınlık (LY) } \\
\text { •Demiryoluna } \\
\text { Yakınlık(DY) } \\
\text { •Otoyollara } \\
\text { Yakınlık } \\
\text { •UA } \\
\text { Ulaştırma } \\
\text { Koridorlarına } \\
\text { Yakınlık }\end{array}$ & $\begin{array}{l}\text {-Çevresel } \\
\text { Etkiler } \\
\text {-Kentsel } \\
\text { Trafiğe } \\
\text { Etkisi } \\
\text { •Ekonomik } \\
\text { Yaşama } \\
\text { Etkisi }\end{array}$ \\
\hline
\end{tabular}

\subsection{AHP Uygulama Aşamaları}

Uygulamanın bu aşamasında kullanılan AHP yönteminin hesaplamaları için Expert Choice 11. yazılımı kullanılmıştır.

Modelde kullanılan kriterlerin belirlenmesi aşamasında, ilk olarak literatür taraması yapılmış daha sonra 20 seneden fazla tekstil sektöründe faaliyet gösteren 5 firmanın yetkilileriyle yüzyüze görüşmeler gerçekleştirilerek onların uzman görüşlerinden istifade edilmiştir.

Uzmanlar ile yapılan görüşmeler neticesinde İstanbul'da faaliyet yürüten tekstil işletmelerinin büyük bir çoğunluğunun Osmanbey, Laleli, Zeytinburnu, Güneşli ve Merter ilçelerinde

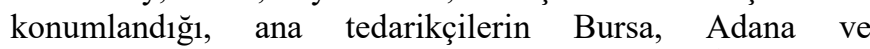
Kahramanmaraş illerinde konumlu oldukları ve İstanbul'un tekstil için uluslar arası pazara çıkış noktası olarak Tuzla ve Harem limanlarının kullanıldığı belirlenmiş ve hesaplamalar bu noktalar düşünülerek gerçekleştirilmiştir. Bu kapsamda uzmanlar ile yapılan görüşmelerde lojistik merkez için uygun yer alternatifleri olarak Halkalı, Tuzla ve Harem ilçeleri belirlenmiştir. $\mathrm{Bu}$ aşamada uzmanlara kuruluş yeri alternatiflerinin çeşitlendirilmesi/fazlalaştırılmasının karar desteği sağlamada fayda sağlayabileceği hatırlatılmışsa da uzmanlar tarafindan gerçek problem sınırları içerisinde analizin gerçekleştirilmesi, sıralanan 3 alternatif dışında bir kurulum yerinin olası görülmediği vurgulanmıştır.

Problemin kriterleri $7 \pm 2$ kuralına göre belirlenmiştir. Hedef, ana ve alt kriterler ile mevcut 3 aday noktayı gösteren AHP yapısı Şekil 4 'te sunulmuştur.

Şekil 4. Hedef, Kriterler ve Alternatifler

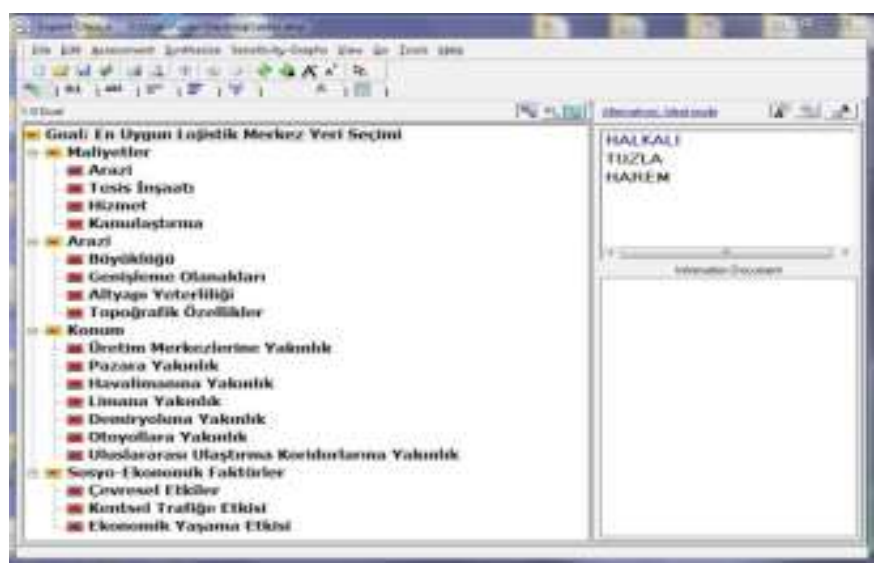

Problemin hiyerarşik modeli 4 Seviyeli olarak kurulmuştur. Her bir ana kriterin farklı sayıda alt kriteri vardır. Model "fayda" yapılı olarak oluşturulmuş olup, ağırlığı en yüksek olan alternatif en iyi seçenek olarak karşımıza çıkmaktadır. Kriterler içinde ise sadece arazi fayda yapıll, diğerlerinin maliyet yapılı olduğu görülmektedir. Buna göre tüm model fayda yapılı olacak şekilde karşılaştırmaların yapılması sağlanmıştır.

\subsubsection{Kriterlerin Ağırlıklandırılması}

Kriterlerin birbirine olan üstünlükleri ikili karşılaştırmalar şeklinde programa girilmiştir. $\mathrm{Bu}$ aşamada tutarsızlığın 0.1 'den kü̧̈ük olması sağlanmıştır.

Şekil 5'te ana kriterlerin ikili karşılaştırmaları örnek olarak sunulmuştur. Ana kriterlerin önem dereceleri değerlendirildiğinde; sırasıyla "Konum, Maliyetler, Arazi ve Sosyo-Ekonomik Faktörler" şeklinde olduğu görülmektedir. 
Şekil 5. Ana Kriterlerin İkili Karşılaştırılması

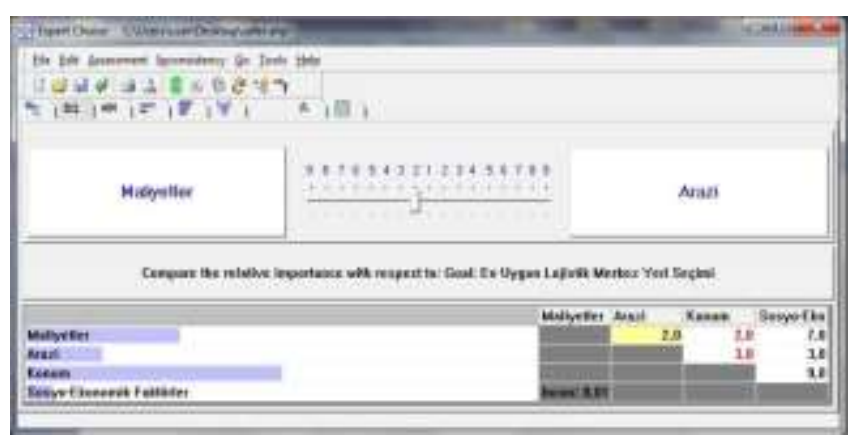

Çalışmada elde edilen alt kriterlere ait ikili karşılaştırma matrisleri Tablo 3-(a,b,c,d)'de sunulmuştur. AHP yöntemine uygun şekilde uzmanların görüşlerinin geometrik ortalaması alınarak en yakın tamsayıya yuvarlanmış ve Expert Choice programına tabloda verilen puanlar girilmiştir.

Tablo 3. Alt Kriterlerin İkili Karşılaştırma Matrisleri

(a) Maliyetler ana kriterinin alt kriterlerinin ikili karşılaştırması

\begin{tabular}{lcccc} 
& Arazi & $\begin{array}{c}\text { Tesis } \\
\text { İnşaatı }\end{array}$ & Hizmet & Kamulaştırma \\
\hline Arazi & & 5 & 3 & $1 / 3$ \\
\hline Tesis İnşaatı & $1 / 5$ & & $1 / 3$ & $1 / 9$ \\
\hline Hizmet & $1 / 3$ & 3 & & $1 / 7$ \\
\hline Kamulaştırma & 3 & 9 & 7 & \\
\hline
\end{tabular}

(b) Arazi ana kriterinin alt kriterlerinin ikili karşılaştırması

\begin{tabular}{lcccc}
\hline & Büyüklüğü & $\begin{array}{c}\text { Genişleme } \\
\text { Olanaklar1 }\end{array}$ & $\begin{array}{c}\text { Altyap1 } \\
\text { Yeterliliği }\end{array}$ & $\begin{array}{c}\text { Topoğrafik } \\
\text { Özellikler }\end{array}$ \\
\hline Büyüklüğü & & 5 & $1 / 5$ & 3 \\
\hline $\begin{array}{l}\text { Genişleme } \\
\text { Olanakları }\end{array}$ & $1 / 5$ & & $1 / 9$ & $1 / 2$ \\
\hline $\begin{array}{l}\text { Altyap1 } \\
\text { Yeterliliği }\end{array}$ & 5 & 9 & & 8 \\
\hline $\begin{array}{l}\text { Topoğrafik } \\
\text { Özellikler }\end{array}$ & $1 / 3$ & 2 & $1 / 8$ & \\
\hline
\end{tabular}

(c) Konum ana kriterinin alt kriterlerinin ikili karşılaştırması

\begin{tabular}{lccccc}
\hline & ÜMY & PY & HY & LY & DY \\
\hline ÜMY & & 3 & 9 & 6 & 6 \\
\hline PY & $1 / 3$ & & 9 & 6 & 6 \\
\hline HY & $1 / 9$ & $1 / 9$ & & $1 / 9$ & $1 / 3$ \\
\hline LY & $1 / 6$ & $1 / 6$ & 9 & & 2 \\
\hline DY & $1 / 6$ & $1 / 6$ & 3 & $1 / 2$ & \\
\hline
\end{tabular}

(d) Sosyo-ekonomik ana kriterinin alt kriterlerinin karşıılaştırması

\begin{tabular}{llll} 
& $\begin{array}{l}\text { Çevresel } \\
\text { Etkiler }\end{array}$ & $\begin{array}{l}\text { Kentsel Trafiğ } \\
\text { Etkisi }\end{array}$ & $\begin{array}{l}\text { Ekonomik } \\
\text { Yaşama Etkisi }\end{array}$ \\
\hline Çevresel Etkiler & & $1 / 2$ & $1 / 5$ \\
\hline $\begin{array}{l}\text { Kentsel Trafiğe } \\
\text { Etkisi }\end{array}$ & 2 & & $1 / 2$ \\
\hline $\begin{array}{l}\text { Ekonomik } \\
\text { Yaşama Etkisi }\end{array}$ & 5 & 2 & \\
\hline
\end{tabular}

Ana kriterlerden "Maliyetler" kriterinin alt kriterleri ve önem dereceleri (Local:L - Global:G olarak) Şekil 6'da sunulmuştur. $\mathrm{Bu}$ kriter açısından en iyi alternatif Tuzla $(0,512)$ olarak elde edilmiştir.

“Arazi” kriterine ait alt kriterler ve önem dereceleri Şekil 7'de sunulmuştur. Bu kriter açısından en iyi alternatif Tuzla $(0,581)$ olarak elde edilmiştir. Bu kriterin ağırlıklandırılmasında uzman görüşlerine başvurulmuştur.

"Konum" kriterine ait alt kriterler ve önem dereceleri Şekil 8 'de sunulmuştur. Bu kriter açısından en iyi alternatif Tuzla $(0,427)$ olarak elde edilmiştir. $\mathrm{Bu}$ kriterin ağırlıklandırılmasında Google Maps uygulamasının "Yol
Tarifi Al" komutu kullanılarak yukarıda belirtilen kümelenme noktalarının gerçek mesafeleri modele girilmiştir.

Şekil 6. Maliyetler Kriteri

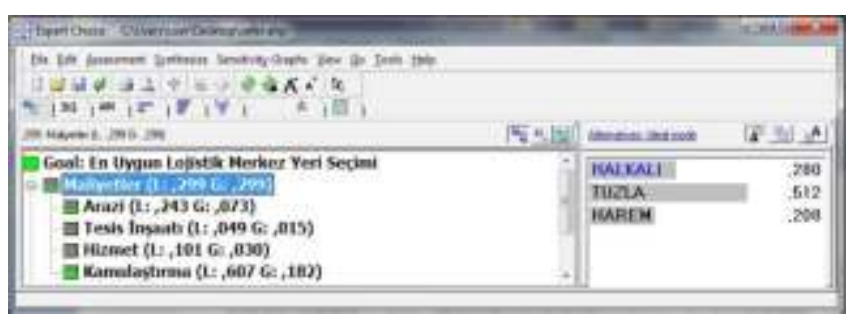

Şekil 7. Arazi Kriteri

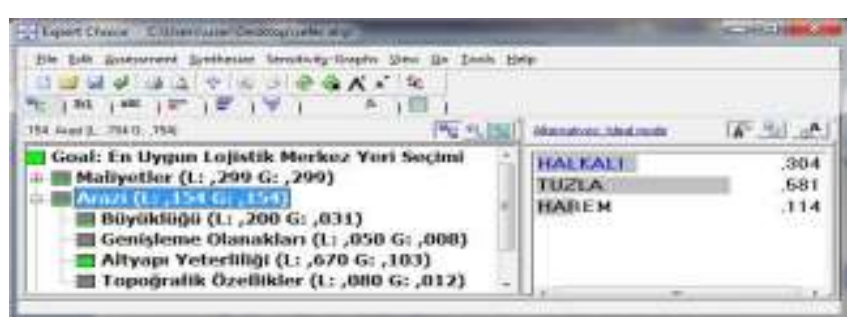

Sekil 8. Konum Kriteri

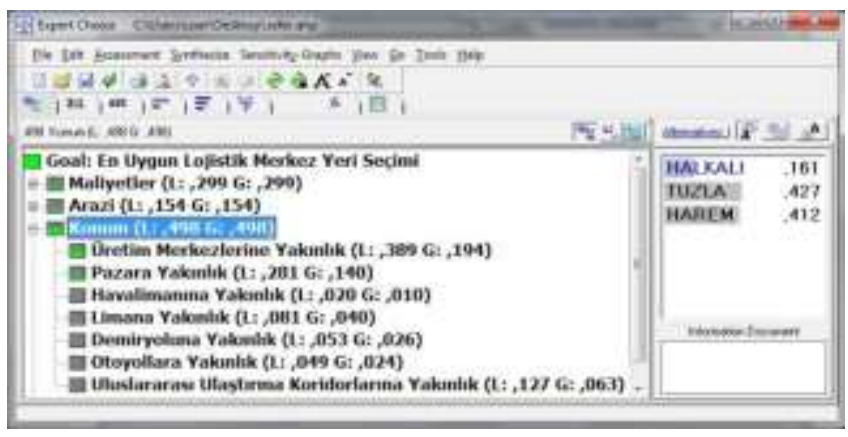

“Sosyo-Ekonomik Faktörler" kriterine ait alt kriterler ve önem dereceleri Şekil 9'da sunulmuştur. Bu kriter açısından en iyi alternatif Tuzla $(0,563)$ olarak elde edilmiştir. Bu kriterin ağırlıklandırılmasında uzman görüşlerine başvurulmuştur.

\section{Şekil 9. Sosyo-Ekonomik Faktörler Kriteri}

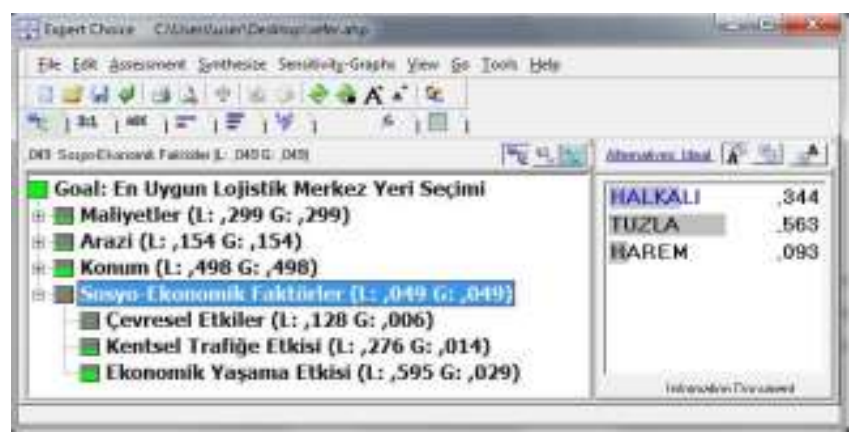

\subsubsection{Tutarsızlığın Giderilmesi}

Tutarsızlığın 0.1 'den büyük olduğu durumlarda programın INCONSISTENCY menüsünden BEST FIT seçeneği ile tutarsızlık yaratan değerin düzeltilmesi sağlanmıştır. Bu aşamada uzman görüşleri ve gerçek verilerden sapmalar oluşmaması için bazı kriterlerin tutarsızlığ $\breve{1}_{1}$ daha da düşürülebilecekken 0.10 'un altında kalması yeterli görülmüş daha da düşürülmesine çalışılmamıştır. Örneğin arazi 
kriterinin başlangıçta 0,11 olan tutarsızlık değeri Şekil 10'daki işlem gerçekleştirilerek 0,08 'e düşürülmüştür.

Şekil 10. Tutarsızlığın giderilmesi

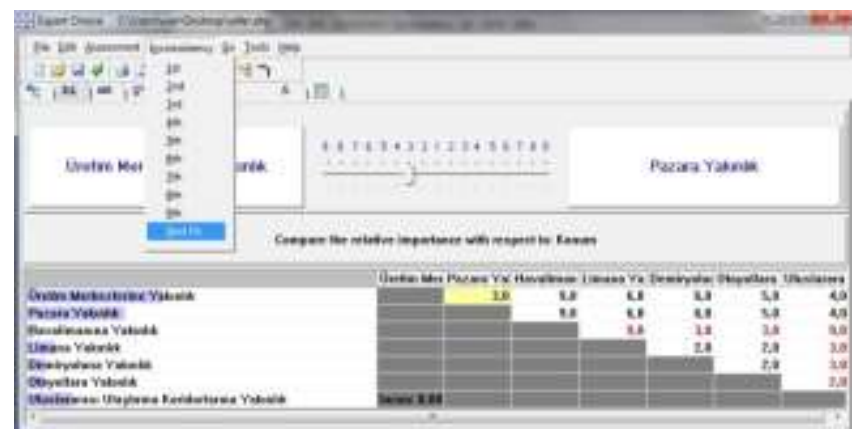

Üç alternatif arasından yapılan yer seçimi çalışmasının sonuçları Şekil 11'de gösterilmiştir.

Şekil 11. Model Sonuçları

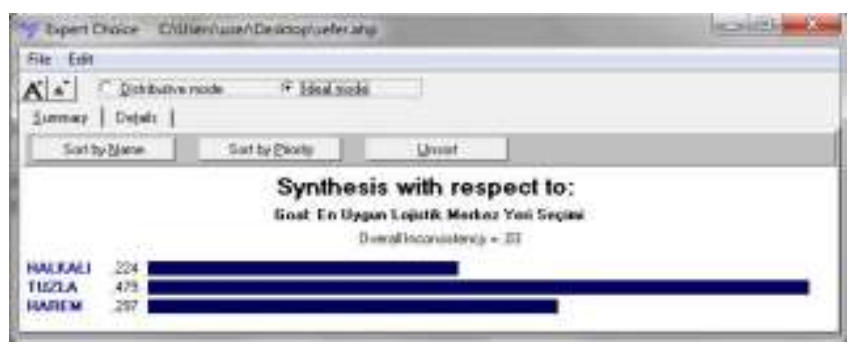

Buna göre LM kurmak için en uygun alternatifin Tuzla olduğu, diğer iki alternatifin birbirine çok yakın değerlere sahip olduğu tespit edilmiştir.

\section{Sonuç ve Öneriler}

Çözüm için uygulanan AHP yöntemi analiz bölümünde bahsedildiği şekilde çok sayıda tesis yeri seçimi problemi için kullanılmış ve başarısı kanıtlanmış bir yöntemdir. Yöntemin Şekil 1 ve 2'den artan bir şekilde kullanılmaya devam ettiği görülmektedir. Nitel ve Nicel verilerin bir arada kullanılma zorunluluğu ve uzman görüşlerine başvurma zorunluluğu da bu çalışmada bu yöntemin kullanılmasının diğer nedenleridir. Modelin çözüm aşamasında AHP yönteminin gereği olarak gerçekleştirilen tutarlılık analizi, kriterlerin birbirlerine göre önem derecelendirmesi aşamasında girilen verilerin ve uzmanların tutarlı bilgi vermesini ve eksik yargı kalmamasını sağlaması bakımından modelin geçerliliğini sağlamaktadır.

Çalışmada lojistik sistemin en önemli unsurlarından LM yer seçiminin şirketin başarısını etkileyen önemli bir araç olduğu belirtilmiştir. Uygun bir konum seçimi, gelecekteki işi ve uzun vadeli karlılığı etkilediği için kritik bir karardır (Chen ve Qu, 2006) ve ülkemiz için önemli sektörlerden olan tekstil sektörüne yönelik olarak LM kurulması kazandıracağı faydalar açısından bu çalışmada ele alınmıştır. Çalışmada AHP yönteminin uygulanmasıyla elde edilen sonuçların daha önce bahsedilen 5 yöneticiyle paylaşılması sonucu yöneticiler de sonuçları uygun bulmuş ve bu açıdan modelin geçerliliği anlaşılmaktadır.

Günümüzde, ÇKKV problemlerinde dilsel değişkenlerin ifade edilebilmesi için bulanık sayılardan faydalanılmaktadır. $\mathrm{Bu}$ çalışmanın devamının bulanık sayılarla gerçekleştirilmesi planlanmaktadir.

\section{Kaynakça}

Atabay, İ. (2005). İhracatçı İşletmeler ile İhracatçı Olmayan Işletmeler Arasındaki Farkllliklar ve İhracat Performansının Analizi: Zeytinyağl Sektöründe Bir Inceleme. (Yayınlanmamış Doktora Tezi), Gebze Yüksek Teknoloji Üniversitesi Sosyal Bilimler Enstitüsü. Gebze.

Aydın, G.T. ve Öğüt, K.S. (2008). Avrupa ve Türkiye'de Lojistik Köyleri. 2. Uluslararası Demiryolu Sempozyumu, Istanbul. 2. Cilt, 1471-1481.

Bozorgi-Amiri, A., Asvadi, S. (2015). A prioritization model for locating relief logistic centers using analytic hierarchy process with interval comparison matrix. KnowledgeBased Systems, 86, 173-181.

Chen, Y., Qu, L. (2006). Evaluating the selection of logistics centre location using fuzzy MCDM model based on entropy weight. In Intelligent Control and Automation, 2006. WCICA 2006. The Sixth World Congress on (Vol. 2, 7128-7132). IEEE.

Farahani, R. Z., SteadieSeifi, M., Asgari, N. (2010). Multiple criteria facility location problems: A survey. Applied Mathematical Modelling, 34(7), 1689-1709.

Huang, H., Zhu, Y. (2014). The location of logistics center by AHP-GP based on convenient idea. Journal of Chemical and Pharmaceutical Research, 6(7):1098-1102.

İstanbul Tekstil ve Konfeksiyon İhracatçı Birlikleri (İTKİB) resmi internet sayfasi, (http://www.itkib.org.tr/itkib/UyeListeleri/data/itkib_uye_ liste.xls), Erişim tarihi: 06.11.2018.

Lee, Y., Kozar, K. A. (2006). Investigating the effect of website quality on e-business success: An analytic hierarchy process (AHP) approach. Decision support systems, 42(3), 1383-1401.

Li, Y., Liu, X., Chen, Y. (2011). Selection of logistics center location using Axiomatic Fuzzy Set and TOPSIS methodology in logistics management. Expert Systems with Applications, 38(6), 7901-7908.

Li-li, Q., Yan, C. (2007). An interactive integrated MCDM based on FANN and application in the selection of logistic center location. In Management Science and Engineering, 2007. ICMSE 2007. International Conference on (162167). IEEE.

Liu, X., Guo, X., Zhao, X. (2012). Study on Logistics Center Site Selection of Jilin Province. JSW, 7(8), 1799-1806.

Önden, İ., Acar, A. Z., Eldemir, F. (2016). Evaluation of the logistics center locations using a multi-criteria spatial approach. Transport, 33(2), 1-13.

Pramanik, S., Dalapati, S., Roy, T. K. (2016). Logistics center location selection approach based on neutrosophic multicriteria decision making. New trends in neutrosophic theory and applications, Brussells, Pons Editions, 161174.

Regmi, M. B., Hanaoka, S. (2013). Location analysis of logistics centres in Laos. International Journal of Logistics Research and Applications, 16(3), 227-242. 
Saaty, T., L. (1990). How to Make a Decision: The Analytic Hierarchy Prosess. European Journal of Operational Research, 48, 15.

Saygılı, M. S. (2014). Intermodal taşımacılığın maliyet avantajları: Karayolu-denizyolu entegrasyonu üzerine bir araştırma. Öneri Dergisi, 11(41), 203-214.

Tang, X. L. (2016). Logistics Network Construction of Hazardous Goods Based on Analytic Hierarchy Process. Chemical Engineering Transactions, 55, 463-468.

Tanyaş, M. ve Arıkan, F., (2013). Bursa İli Lojistik Merkez Ön Fizibilite Raporu. Bursa Sanayici ve İş Adamları Derneği, Bursa.

Tomić, V., Marinković, D., Marković, D. (2014). The selection of logistic centers location using multi-criteria comparison: case study of the Balkan Peninsula. Acta Polytechnica Hungarica, 11(10), 97-113.

Tu, C. S., Chang, C. T., Chen, K. K., Lu, H. A. (2010). Applying an AHP-QFD conceptual model and zero-one goal programming to requirement-based site selection for an airport cargo logistics center. International Journal of Information and Management Sciences, 21(4), 407-30.
Tuğba Turğut, B., Taş, G., Herekoğlu, A., Tozan, H., Vayvay, O. (2011). A fuzzy AHP based decision support system for disaster center location selection and a case study for Istanbul. Disaster Prevention and Management: An International Journal, 20(5), 499-520.

Turskis, Z., Zavadskas, E. K. (2010). A new fuzzy additive ratio assessment method (ARAS-F). Case study: The analysis of fuzzy multiple criteria in order to select the logistic centers location. Transport, 25(4), 423-432.

Wang, Y. J., Han, T. C., Chou, M. T. (2016). Applying fuzzy AHP in selection of transport modes for Kinmen military logistics. Journal of Marine Science and Technology, 24(2), 222-232.

Żak, J., Węgliński, S. (2014). The selection of the logistics center location based on MCDM/A methodology. Transportation Research Procedia, 3, 555-564.

Zhang, C., Pan, D. H. (2007). An Evaluation Model Based on Fuzzy Rule for Logistics Centers. Journal-Northeastern University Natural Science, 28(4), 596. 